\title{
Communication
}

\section{Proposed "Biosynthesis" of Primarolides A and B from a Common 2-Formylbenzophenone Precursor}

\author{
Hans-Günther Schmalz* \\ 1 University of Cologne, Department of Chemistry, Greinstrasse 4, 50939 Köln, Germany \\ * Correspondence: schmalz@uni-koeln.de; Tel.: +49-221-470-3063 (H.-G.S.)
}

\begin{abstract}
The structures of recently discovered primarolides A and B suggest their non-enzymatic formation from a common 2-formylbenzophenone precursor. This hypothesis is based on the experimentally proven facile conversion of pestalone (also a 2-formyl-benzophenone) either into the isomeric lactone pestalalactone or the structurally related isoindolinone pestalachloride A. In a related fashion, the racemic isoindolinone natural product mariline $\mathrm{A}$ is supposed to biosynthetically originate from the corresponding keto-aldehyde and an aniline, as experimentally supported by model studies. Due to the close structural relationship with known systems, it appears highly probable that primarolides A and B were generated under the fermentation conditions from a massarinin-related 2-formylbenzophenone (proprimarolide) by reaction either with aniline or a nucleophilic catalyst, respectively. Suberoylanilide hydroxamic acid (SAHA), used as an additive during the fermentation, is supposed to act both as a source of aniline and as a nucleophilic catalyst.
\end{abstract}

Keywords: lactones; lactames; isoindolinones; non-enzymatic biosynthesis; benzophenones; polyketides; reactive natural products; SAHA; aniline, hydroxamic acids

\section{Introduction}

Recently, Kerr and coworkers reported the discovery of primarolides A (1) and B (2) from a fermentation of the marine fungus Asteromyces cruciatus under $\mathrm{NaCl}$-induced osmotic stress and in the presence of suberoylanilid hydroxamic acid (SAHA) as an epigenetic modifier (histone deacetylase inhibitor) upregulating the expression of silent secondary metabolites (Figure 1).[1]

The structural relationship of the two natural products $\mathbf{1}$ and $\mathbf{2}$, which only differ in the nature of the heterocyclic ring (lactone versus lactam), suggests their formation from a common precursor. Based on our experience with related systems we here propose mechanistically reasonable pathways which could explain the generation of both primarolides in a non-enzymatic fashion from a reactive 2-formyl-benzophenone precursor.

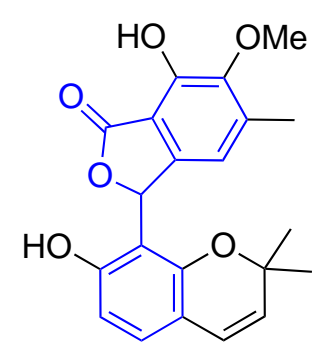

primarolide $\mathrm{A}(\mathbf{1})$<smiles>COc1c(C)cc2c(c1O)C(=O)N(c1ccccc1)C2c1c(O)ccc2c1OC(C)(C)C=C2</smiles>

primarolide B (2)<smiles>O=C(CCCC(=O)Nc1ccccc1)NO</smiles>

SAHA: suberoylanilide hydroxamic acid (3)

Figure 1. Structures of primarolides A and B.

In a more general fashion, the aim of this contribution is also to emphasize and create awareness for the inherent chemical reactivity of 2-acylbenzaldehydes, which occasionally occur as products or intermediates in polyketide biosynthesis and might be involved in non-enzymatic transformations. 


\section{Results and Discussion}

Pestalone (4) was isolated in 2001 by Fenical and coworkers as a metabolite produced by a marine fungus of the genus Pestalotia in response to bacterial challenge (Figure 2).[2] Due to its pronounced antibiotic activity the authors indicated that this compound should be evaluated in advanced models of infectious disease. In the course of our research into the total synthesis of pestalone (3), we accidentally discovered its facile conversion into the isomeric compound pestalalactone (rac-5).[3] Moreover, we found that pestalone readily reacts with ammonia to afford the corresponding lactam pestalachloride A ( $\mathrm{rac}-6)$, which had been isolated by Che and coworkers as an antifungal metabolite from the plant endophytic fungus Pestalotiopsis adusta.[4]<smiles>COc1c(Cl)c(C)c(Cl)c(O)c1C(=O)c1c(CO)c(O)cc(O)c1CC=C(C)C</smiles>

pestalone (4)<smiles>COc1c(Cl)c(C)c(Cl)c(O)c1C1OC(=O)c2c(O)cc(O)c(CC=C(C)C)c21</smiles>

pestalalactone (rac-5)<smiles>COc1c(Cl)c(C)c(Cl)c(O)c1C1NC(=O)c2c(O)cc(O)c(CC=C(C)C)c21</smiles>

pestalalachloride $A$ (rac-6)

Figure 2. Structures of pestalone, pestalalactone and pestalachloride A.

The fact that pestalachloride A (rac-6) (and its congeners) were isolated as racemic mixtures indicated their non-enzymatic formation from an achiral precursor. In a similar fashion, marilins AC (rac-7-9; Figure 3), isolated by König and coworkers from the sponge-derived fungus Stachylidium sp., were obtained in racemic form - despite their proven configurational stability.[5] Therefore, the authors mentioned the possibility that the marilines might be generated through a condensation process from a keto-aldehyde similar to the formation of pestalachloride A (rac-6) from pestalone (4).

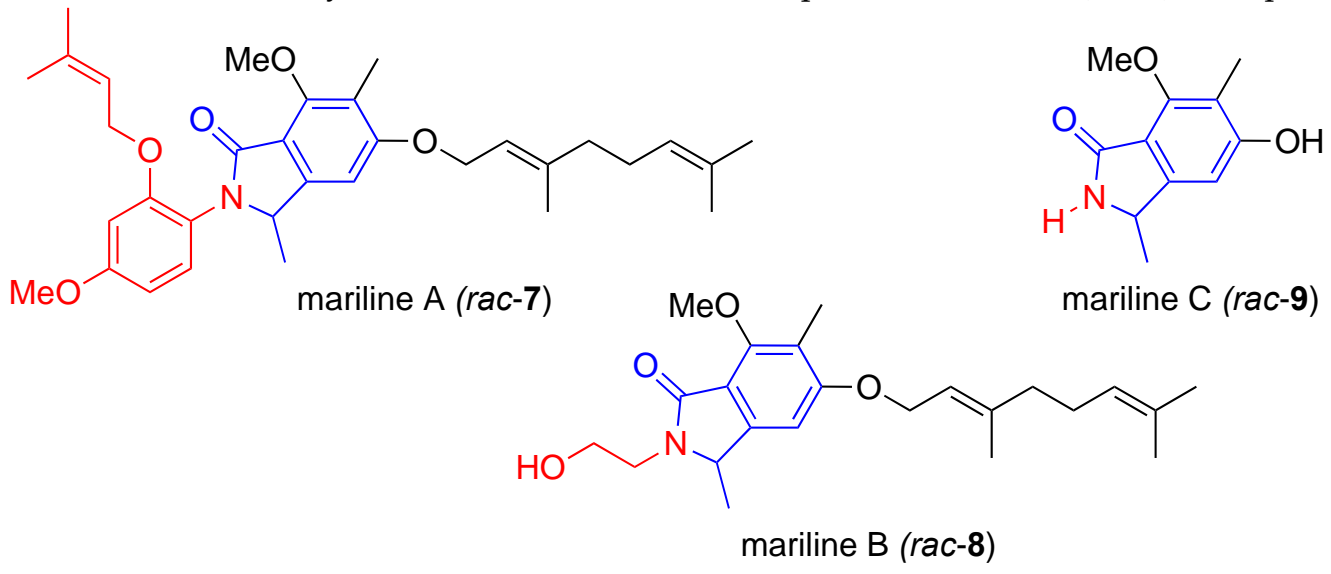

Figure 3. Structures of marilines A, B and C.

To probe the generality of the underlying chemical transformations and to shed light on the involved mechanisms we performed separate studies employing a set of synthetic model substrates of type 10 all sharing the characteristic (reactive) 2-formylarylketone (i.e. 2-acylbenzaldehyde) moiety (Scheme 1).[6,7] As a result we could demonstrate that the formation of lactones of type rac-11 is efficiently mediated by nucleophilic catalysts (such as cyanide or thiolate salts) under mild conditions. Interestingly, the conversion of $\mathbf{1 0}$ to rac-11 also occurs upon irradiation with UV light (350 nm).[6] Moreover, the condensation of 2-formylarylketones (10) with primary amines (including amino acid esters) was found to proceed smoothly at room temperature, preferentially under slightly acidic conditions to afford isoindolinones rac-12.[7] The simplified mechanisms for both transformations are shown in Scheme 1. While an intramolecular hydride transfer, i.e. a Cannizarro- 
Tishchenko-type reaction, is involved in the nucleophile-catalyzed lactone formation, the reaction of 10 with primary amines most probably proceeds through hemiacetal formation, water elimination and tautomerization of an isoindole intermediate (Scheme 1).<smiles>[R7]C1OC(=O)c2ccccc21</smiles><smiles>[R]C(=O)c1ccccc1CCCC(=O)O</smiles><smiles>[R10]C1NC(=O)c2ccccc21</smiles>

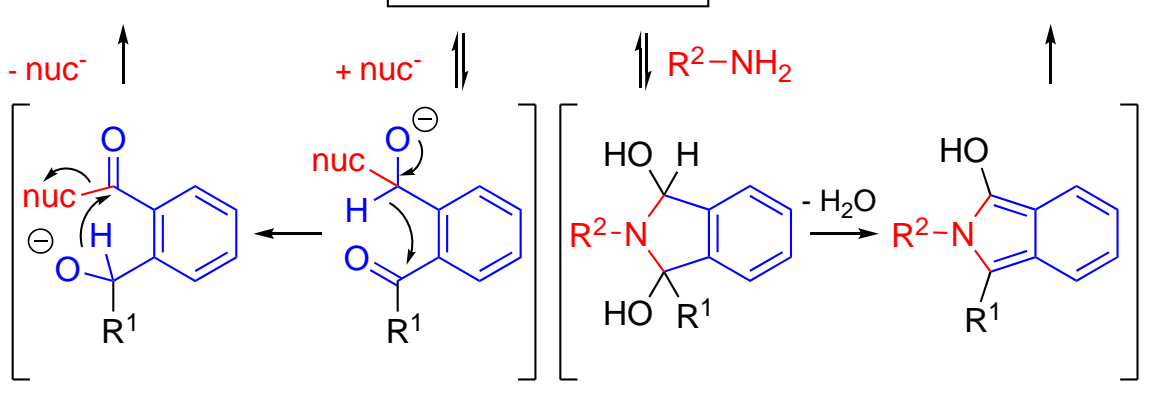

Scheme 1. Chemical conversion of 2-formylarylketones of type $\mathbf{1 0}$ into the isomeric lactones of type rac-11 or into isoindolinones of type rac-12.

More specifically, we provided evidence for the non-enzymatic formation of marilines A and B (rac-7/8) through condensation of the aniline $\mathbf{1 3}$ with the 2-formylacetophenone derivative $\mathbf{1 4}$ in a remarkably clean and fast reaction (Scheme 2).[8]. Noteworthy, the same concept was later exploited by Seidel and coworkers in an enantioselective "biomimetic" synthesis of mariline A.[9]<smiles>COc1ccc([NH3+])c(OCC=C(C)C)c1</smiles>

13<smiles>COc1cc(C(C)=O)c(C=O)c(OC)c1C</smiles>

14<smiles>COc1ccc(N2C(=O)c3c(cc(OC)c(C)c3OC)C2C)c(OCC=C(C)C)c1</smiles>

rac-15

Scheme 2. $\mathrm{N}$-Capping of the aniline $\mathbf{1 3}$ by the 2 -formylarylketone $\mathbf{1 4}$ to yield the mariline A related isoindolinone $\mathrm{rac}-\mathbf{1 5}$.

Against this background it appears highly probable that primarolides A and B both arise from proprimarolide (16) as a common precursor as shown in Scheme 3. Regarding the pronounced $\alpha$ nucleophilicity of hydroxamic acids[10] one can expect suberoylanilid hydroxamic acid (SAHA, 3), present as an additive, to assist as a nucleophilic catalyst in the formation of lactone rac-1. In accordance to other recent reports on the isolation of aniline-derived natural products from fungi cultured in the presence of SAHA (3) [11-13] one can also assume that aniline is readily formed from SAHA (3) under the action of fungal amidohydrolases. Thus, the reaction of $\mathbf{1 6}$ with aniline would directly give rise to racemic primarolide B ( $r a c-2)$ according to the above-mentioned reaction path. 
<smiles>[R]C(=O)NO</smiles>

primarolide A (rac-1)

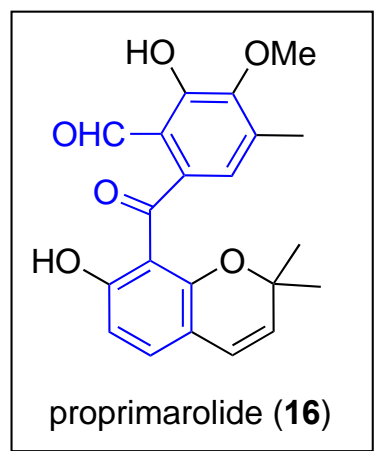<smiles>COc1c(C)cc2c(c1O)C(=O)N(c1ccccc1)C2c1c(O)ccc2c1OC(C)(C)C=C2</smiles>

primarolide B (rac-2)

Scheme 3. Proposed non-enzymatic formation of racemic primarolides A and B from proprimarilde (16) as a common precursor, either by nucleophilic catalysis or by condensation with aniline.

It therefore seems highly probable that under the stress conditions used by Kerr and coworkers Asteromyces cruciatus produces proprimarolide (16) which directly further reacts to the observed metabolites. Besides its role as a histone deacetylase inhibitor SAHA is supposed to act as both a nucleophilic catalyst and a source of aniline. The function of $\mathrm{NaCl}$ remains speculative: While the osmotic stress may contribute to the expression of $\mathbf{1 6}$ the increased salt concentration may also accelerate the subsequent nonenzymatic processes (compare Scheme 1) by stabilizing charges intermediates and promoting the dehydration step required for lactame formation. In any case, it can be predicted (and possibly experimentally verified) that the primarolides are formed and isolated as racemic mixtures.

\section{Conclusions}

The research results collected and discussed above form a case study which clearly proves the importance of 2-formylarylketones in natural products chemistry. Metabolites, such as pestalone (4) and the related compounds massarinin A (17)[14] and tennelone A (18)[15] can exhibit strong biological activity on their own (Figure 4). However, such compounds are prone to react with primary amines giving rise to racemic isoindolinones ( $r a c-19 ; X=N R)$ in rapid non-enzymatic processes. Thus, as in the "biosynthesis" of pestalachloride or the marilines, the 2-formylarylketone intermediates may reveal their (transient) existence only indirectly in form of the stable isoindolinone (or lactone) derivatives. The inherent reactivity/chemical instability of such natural products should also be taken into account during their biological characterization in order to avoid the uncontrolled generation of derivatives with different biological activities.[16]<smiles>COc1c(C)cc(O)c(C(=O)c2c(O)ccc3c2OC(C)(C)C=C3)c1C=O</smiles>

massarinin $A(17)$<smiles>CC(C)=CCc1ccc(O)c(C=O)c1C(=O)c1cc(C)cc(OCC(O)C(C)(C)O)c1O</smiles>

tenellone $\mathrm{A}(\mathbf{1 8})$<smiles>[R]c1ccc(C2[Y]C(=O)c3ccccc32)cc1</smiles>

$\operatorname{rac}-19(\mathrm{X}=\mathrm{O}$ or $\mathrm{NR})$

Figure 4. Massarinin A (17) and tenellone A (18) as natural 2-formylbenzophenones related to pestalone (4) and proprimarolide (16) which also could easily further react to give rise to heterocyclic derivatives of type rac-19.

Author Contributions: This communication was conceptualized and written solely by H.-G.S.

Acknowledgments: In this section you can acknowledge any support given which is not covered by the author contribution or funding sections. This may include administrative and technical support, or donations in kind (e.g., materials used for experiments). 
Conflicts of Interest: “The author declares no conflict of interest.”

\section{References}

1. Igboeli, H. A.; Marchbank, D. H.; Correa, H.; Overy, D.; Kerr, R. G. Discovery of Primarolides A and B from Marine Fungus Asteromyces cruciatus Using Osmotic Stress and Treatment with Suberoylanilide Hydroxamic Acid. Mar. Drugs 2019, 17, 435.

2. Cueto, M.; Jensen, P. R.; Kauffman, C.; Fenical, W.; Lobkovsky, E.; Clardy, J. Pestalone, a New Antibiotic Produced by a Marine Fungus in Response to Bacterial Challenge. J. Nat. Prod. 2001, 64, 1444-1446.

3. Slavov, N.; Cvengros, J.; Neudörfl, J.-M.; Schmalz, H.-G. Total Synthesis of the Marine Antibiotic Pestalone and its Surprisingly Facile Conversion into Pestalalactone and Pestalachloride A. Angew. Chem. Int. Ed. 2010, 49, $7588-7591$.

4. Li, E.; Jiang, L.; Guo, L.; Zhang, H.; Che, Y. Pestalachlorides A-C, antifungal metabolites from the plant endophytic fungus Pestalotiopsis adusta. Bioorg. Med. Chem. 2008, 16, 7894-7899.

5. Almeida, C.; Hemberger, Y.; Schmitt, S. M.; Bouhired, S.; Natesan, L.; Kehraus, S.; Dimas, K.; Gütschow, M.; Bringmann, G.; König, G. M. Marilines A-C: Novel Phthalimidines from the Sponge-Derived Fungus Stachylidium sp. Chem. Eur. J. 2012, 18, 8827-8834.

6. Augner, D.; Gerbino, D. C.; Slavov, N.; Neudörfl, J.-M.; Schmalz, H.-G. N-Capping of Primary Amines with 2-Acylbenzaldehydes to Give Isoindolinones. Org. Lett. 2011, 13, 5374-5377.

7. Gerbino, D. C.; Augner, D.; Slavov, N.; Neudörfl, J.-M.; Schmalz, H.-G. Nucleophile- or Light-Induced Synthesis of 3-Substituted Phthalides from 2-Formylarylketones. Org. Lett. 2012, 114, 2338-2341.

8. Augner, D. Schmalz, H.-G. Biomimetic Synthesis of Isoindolinones Related to the Marilines. Synlett 2015, 26, 1395-1397.

9. Min, C.; Lin, Y.; Seidel, D. Catalytic Enantioselective Synthesis of Mariline A and Related Isoindolinones through a Biomimetic Approach. Angew. Chem. Int. Ed. 2017, 56, 15353 -15357.

10. Singh, N.; Karpichev, Y.; Sharma, R.; Gupta, B.; Sahu, A. K.; Satnamia, M. L.; Ghosh, K. K. From $\alpha-$ nucleophiles to functionalized aggregates: exploring the reactivity of hydroxamate ion towards esterolytic reactions in micelles. Org. Biomol. Chem. 2015, 13, 2827-2848.

11. Adpressa, D. A.; Stalheim, K. J.; Proteau, P. J.; Loesgen, A. Unexpected Biotransformation of the HDAC Inhibitor Vorinostat Yields Aniline-Containing Fungal Metabolites. ACS Chem. Biol. 2017, 12, 1842-1847.

12. Zhang, Z.; He, X.; Wu, G.; Liu, C.; Lu, C.; Gu, Q.; Che, Q.; Zhu, T.; Zhang, G.; Li, D. Aniline-Tetramic Acids from the Deep-Sea-Derived Fungus Cladosporium sphaerospermum L3P3 Cultured with the HDAC Inhibitor SAHA. J. Nat. Prod. 2018, 81, 1651-1657.

13. Zhang, S.; Fang, H.; Yin, C.; Wei, C.; Hu, J.; Zhang, Y. Antimicrobial Metabolites Produced by Penicillium mallochii CCH01 Isolated from the Gut of Ectropis oblique, Cultivated in the Presence of a Histone Deacetylase Inhibitor. Front. Microbiol. 2019, 10, article 2186 (doi: 10.3389/fmicb.2019.02186).

14. Oh, H.; Swenson, D. C.; Gloer, J. B.; Shearer, C. A. New Bioactive Rosigenin Analogues and Aromatic Polyketide Metabolites from the Freshwater Aquatic Fungus Massarina tunicate. J. Nat. Prod. 2003, 66, 7379.

15. Zhang, C.; Ondeyka, J. G.; Herath, K. B.; Guan, Z.; Collado, J.; Platas, G.; Pelaez, F.; Leavitt, P. S.; Gurnett, A.; Nare, B.; Liberator, P.; Singh, S. B. Tenellones A and B from a Diaporthe sp.: Two Highly Substituted Benzophenone Inhibitors of Parasite cGMP-Dependent Protein Kinase Activity. J. Nat. Prod. 2005, 68, 611613.

16. Augner, D.; Krut, O.; Slavov, N.; Gerbino, D. C.; Sahl, H.-G.; Benting, J.; Nising, C. F.; Hillebrand, S.; Krönke, M.; Schmalz, H.-G. On the Antibiotic and Antifungal Activity of Pestalone, Pestalachloride A, and Structurally Related Compounds. J. Nat. Prod. 2013, 76, 1519-1522. 